DOI: 10.19085 /journal.sijbpg030202

\title{
Public procurement: A public policy tool for resources management
}

\author{
Ko Hoon Lee \\ Doctoral candidate, Thammasat University, Bangkok, Thailand.
}

OScholedge International Journal of Business Policy \& Governance (ISSN 2394-3351), Vol.03, Issue 02 (2016) pg13-16. Published by: Scholedge R\&D Center [www.theSCHOLEDGE.org] [Email: sijbpg@scholedge.org]

\begin{abstract}
The United Nations assesses that defilement, pay off, robbery, and duty avoidance cost creating nations about $\$ 1.26$ trillion every year. That is double the total national output of all of Asia. These are calming numbers undoubtedly. No one precisely knows exactly how much, yet a genuinely substantial part of the misfortune will be from failures in broad public procurement.
\end{abstract}

Keywords: Public procurement, public policy, challenges, resources management

\section{Introduction}

Bhutan—a nation that emerges in Asia and the Pacific as being seen to have low levels of defilement and blunder in people in general area-very nearly 20\% of aggregate abnormalities in 2014 at the national level were because of what the Royal Audit Authority calls 'slips in acquirement standards' (see figure). In the previous six years since the most recent information is accessible, this is a normal of just about $15 \%$.

In the event that in Bhutan—where these issues are thoroughly implemented—slips in acquisition add up to $15 \%$ of aggregate abnormalities, the number will undoubtedly be higher in different nations.

This is the reason $A D B$ considers dangers in acquisition as one of three administration dangers to be figured in while surveying the dangers to improvement adequacy in all its nation association systems and in venture programs. Governments over the world have now started to investigate how they can enhance their acquirement frameworks. Here are three of the more imperative issues they should remember. 
Openness in acquisition. Being straightforward about acquisition matters has ended up being the single greatest administration issue as of late. The more noteworthy the level of openness, the more there is a correlative propensity for the framework to be overseen appropriately. This openness alludes to what the open doors are for tendering offers, who the bidders are for individual activities and works contracts, and what the particular principles and regulations are for all players in this market (this requirement for a level playing field is an essential thought in guaranteeing that the framework is trusted by all gatherings). This straightforwardness permits the general population to consider responsible government authorities that are depended with overseeing open obtainment. One of the all the more every now and again utilized devices to do as such nowadays is e-acquisition, which permits governments to make acquirement straightforward and proficient. Another route is through a devoted substance, (for example, the Public Procurement Monitoring Office in Nepal, straightforwardly under the Office of the Prime Minister) that screens and openly reports acquisition slips.

Government duty. Being intense with holding fast to the tenets and organizing punishments, as commanded by law, exhibits government duty toward obtainment adequacy. On the off chance that there is one shortcoming that the framework will benefit from, it is the view of absence of solid duty with respect to government when omissions in administration are made open. In nations where there is no acquirement law set up (and open obtainment is represented by different acts, for example, an open money act) it is guaranteed there is less space to manoeuver than in nations where, for example, a demonstration is set up. In any case, valid studies are still required in less-created nation settings to loan confidence to this case.

Limit building. Guaranteeing that open segment authorities at the neighborhood level have the fundamental mindfulness and abilities to do acquirement undertakings as per the law keeps on being a standout amongst the most significant issues that national governments face. The issue of obtainment slips is similarly extreme at the neighborhood government level (though the aggregate level of abnormalities will be lower at that level). As nations keep on decentralizing capacities and assets to neighborhood governments, there will be expanding weight on these nearby level substances, huge numbers of whom won't have satisfactory assets to deal with their acquisition forms proficiently, adequately, and in a straightforward and responsible way.

This is an effective blend - the weight to lapse more power and capacities to nearby governments, however not as a matter of course be in a position to bolster correlative measures, for example, building limit with the goal that acquirement procedures are better overseen. As the experience of even a moderately well-performing framework as that apparent in Bhutan illustrates, not getting this 
comparison right will turn out to be excessive; nations stand to lose a huge number of dollars in the event that they don't get this math right.

To make a level playing field for all organizations crosswise over Europe, EU law sets out least fit open acquisition rules. These principles sort out the way open powers and certain open utility administrators buy products, works and administrations. They are transposed into national enactment and apply to tenders whose money related quality surpasses a specific sum. For tenders of lower worth, national guidelines apply. By the by, these national standards likewise need to regard the general standards of EU law.

E-acquirement alludes to the utilization of electronic interchanges by open segment associations when purchasing supplies and benefits or tendering open works. Expanding the utilization of e-acquirement in Europe can create huge investment funds for European citizens. These investment funds would expand the effectiveness of open spending in the present connection of financial imperatives. Eacquirement can likewise give another wellspring of monetary development and occupations, including by encouraging access to open obtainment decreases by little and medium-sized undertakings.

Representing $15-20 \%$ of worldwide GDP, open acquirement speaks to a significant segment of the EU economy and the economies of numerous nations around the globe. Open acquisition responsibilities under the World Trade Organization's Agreement on Public Procurement (GPA) have been assessed at around EUR 1.3 trillion.

Notwithstanding, as opposed to the EU approach favoring more noteworthy openness, numerous non-EU nations are hesitant to open their open obtainment markets to global rivalry. The EU advocates open universal open acquirement markets for specific merchandise and administrations, and attempts to offer EU some assistance with companying access worldwide open acquisition markets.

The EU additionally teams up with EU competitor nations and potential contender to guarantee that their open obtainment areas are perfect with EU governs, and arranges with different nations in the structure of exchange transactions. It holds administrative dialogs with nations having imperative open obtainment divisions also.

\section{Conclusion}

Acquisition professionals are the primary performers in general society acquirement process. They are in charge of guaranteeing the objective of open acquisition is accomplished. They should addition 
partner's trust and guarantee they completely comprehend the acquirement procedure and standards.

Obtainment experts are straightforwardly and in a roundabout way occupied with the acquisition process, from need appraisal to contract close-out. In spite of the fact that, they are all the more straightforwardly included in the general population acquirement process, they additionally give exhortation and backing amid contract execution.

\section{References}

Edler, J., \& Georghiou, L. (2007). Public procurement and innovation-Resurrecting the demand side. Research policy, 36(7), 949-963.

Edquist, C., \& Hommen, L. (2000). Public technology procurement and innovation (Vol. 16). Springer Science \& Business Media.

Edquist, C., \& Hommen, L. (2000). Public technology procurement and innovation theory. In Public technology procurement and innovation (pp. 5-70). Springer US.

Trionfetti, F. (2000). Discriminatory public procurement and international trade. The World Economy, 23(1), 57-76.

Vaidya, K., Sajeev, A. S. M., \& Callender, G. (2006). Critical factors that influence e-procurement implementation success in the public sector.Journal of public procurement, 6(1/2), 70.

Brammer, S., \& Walker, H. (2011). Sustainable procurement in the public sector: an international comparative study. International Journal of Operations \& Production Management, 31(4), 452-476. 